\title{
Validation of ACE-FTS v2.2 methane profiles from the upper troposphere to the lower mesosphere
}

\author{
M. De Mazière ${ }^{1}$, C. Vigouroux ${ }^{1}$, P. F. Bernath ${ }^{2,14}$, P. Baron ${ }^{3}$, T. Blumenstock ${ }^{4}$, C. Boone ${ }^{2}$, C. Brogniez ${ }^{5}$, V. Catoire $^{6}$, \\ M. Coffey ${ }^{7}$, P. Duchatelet ${ }^{8}$, D. Griffith ${ }^{9}$, J. Hannigan ${ }^{7}$, Y. Kasai ${ }^{3}$, I. Kramer ${ }^{4}$, N. Jones ${ }^{9}$, E. Mahieu ${ }^{8}$, \\ G. L. Manney ${ }^{10,15}$, C. Piccolo ${ }^{11}$, C. Randall ${ }^{16}$, C. Robert $^{6}$, C. Senten ${ }^{1}$, K. Strong ${ }^{12}$, J. Taylor ${ }^{12}$, C. Tétard $^{5}$, \\ K. A. Walker ${ }^{2,12}$, and S. Wood ${ }^{13}$ \\ ${ }^{1}$ Belgian Institute for Space Aeronomy (BIRA-IASB), Brussels, Belgium \\ ${ }^{2}$ Department of Chemistry, University of Waterloo, Waterloo, Ontario, Canada \\ ${ }^{3}$ National Institute of Information and Communications Technology (NICT), Tokyo, Japan \\ ${ }^{4}$ IMK-ASF, Forschungszentrum Karlsruhe and University Karlsruhe, Karlsruhe, Germany \\ ${ }^{5}$ Laboratoire d'Optique Atmosphérique, Université des sciences et technologies de Lille, Lille, France \\ ${ }^{6}$ Laboratoire de Physique et Chimie de l'Environnement, CNRS - Université d'Orléans, Orléans, France \\ ${ }^{7}$ National Center for Atmospheric Research (NCAR), Boulder, CO, USA \\ ${ }^{8}$ Institut d'Astrophysique et de Géophysique, Université de Liège, Liège, Belgium \\ ${ }^{9}$ School of Chemistry, University of Wollongong, Wollongong, Australia \\ ${ }^{10}$ Jet Propulsion Laboratory, California Institute of Technology, Pasadena, CA, USA \\ ${ }^{11}$ Atmospheric, Oceanic and Planetary Physics, University of Oxford, Oxford, UK \\ ${ }^{12}$ Department of Physics, University of Toronto, Toronto, Ontario, Canada \\ ${ }^{13}$ National Institute of Water and Atmospheric Research (NIWA), Lauder, New-Zealand \\ ${ }^{14}$ Department of Chemistry, University of York, Heslington, York, UK \\ ${ }^{15} \mathrm{New}$ Mexico Institute of Mining and Technology, Socorro, NM, USA \\ ${ }^{16}$ Laboratory for Atmospheric and Space Physics and Department of Atmospheric and Oceanic Sciences, University of \\ Colorado, Boulder, CO, USA
}

\begin{abstract}
The ACE-FTS (Atmospheric Chemistry Experiment - Fourier Transform Spectrometer) solar occultation instrument that was launched onboard the Canadian SCISAT-1 satellite in August 2003 is measuring vertical profiles from the upper troposphere to the lower mesosphere for a large number of atmospheric constituents. Methane is one of the key species. The version v2.2 data of the ACE-FTS $\mathrm{CH}_{4}$ data have been compared to correlative satellite, balloonborne and ground-based Fourier transform infrared remote sensing data to assess their quality. The comparison results indicate that the accuracy of the data is within $10 \%$ in the upper troposphere - lower stratosphere, and within $25 \%$ in the middle and higher stratosphere up to the lower mesosphere $(<60 \mathrm{~km})$. The observed differences are generally consistent with reported systematic uncertainties. ACE-FTS is also shown to reproduce the variability of methane in the stratosphere and lower mesosphere.
\end{abstract}

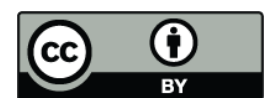

Correspondence to: M. De Mazière (martine@oma.be)

\section{Introduction}

Methane $\left(\mathrm{CH}_{4}\right)$ is the most abundant organic trace gas in the atmosphere. It is the only atmospheric organic compound that has a sufficiently long lifetime (of the order of 8 to 10 years) to be transported from the troposphere to the stratosphere. A discussion of the global cycle of methane can be found, e.g., in Wahlen (1993) and Brasseur et al. (1999). In the troposphere, the volume mixing ratio (VMR) of methane is quite uniform. Yet there is a clear interhemispheric gradient, with present-day VMR values of about $1.7 \mathrm{ppmv}$ in the Southern Hemisphere (SH) and about $1.85 \mathrm{ppmv}$ in the Northern Hemisphere (NH) (GLOBALVIEW-CH4, 2005). This gradient reflects the larger sources of methane in the NH. Thus air entering the stratosphere contains approximately these amounts of methane. The methane abundance also shows a distinct seasonal variation: the net effect of larger sources and stronger chemical losses (see further below) in warmer months gives rise to the largest concentrations in local winter and the lowest concentrations in local summer. The amplitude of the seasonal cycle is largest in the

Published by Copernicus Publications on behalf of the European Geosciences Union. 
northern high latitudes (30-40 ppb) and diminishes towards the equator. It is smaller in the SH (10-20 ppb) where it is quite constant with latitude (Wahlen, 1993).

A common destruction mechanism for methane in the stratosphere and the troposphere is reaction with $\mathrm{OH}$, forming the methyl radical $\mathrm{CH}_{3}$ and water vapour $\left(\mathrm{H}_{2} \mathrm{O}\right)$. Additional sinks in the stratosphere are the reactions with $\mathrm{O}\left({ }^{1} \mathrm{D}\right)$ or $\mathrm{Cl}$ atoms, forming $\mathrm{CH}_{3}$ and $\mathrm{OH}$ or $\mathrm{HCl}$, respectively. Methane is therefore a sink for chlorine atoms in the stratosphere, hence its importance in stratospheric ozone chemistry, and a source of stratospheric water vapour. Chemical destruction of methane in the lower stratosphere is quite slow, because of the low abundances of $\mathrm{O}\left({ }^{1} \mathrm{D}\right)$ and $\mathrm{Cl}$ atoms, and because of the strong temperature dependence of the reaction with $\mathrm{OH}$. Therefore in the low stratosphere, the $\mathrm{CH}_{4} \mathrm{VMR}$ can be used as a tracer of dynamical processes.

In the troposphere, methane is of great importance in tropospheric chemistry, as it usually is the most abundant and certainly the most ubiquitous hydrocarbon. Its oxidation scheme, starting with the reaction with $\mathrm{OH}$, ultimately produces $\mathrm{CO}_{2}$. A major intermediate in the degradation of $\mathrm{CH}_{4}$ is formaldehyde $\left(\mathrm{H}_{2} \mathrm{CO}\right)$. Other oxidation products are carbon monoxide $(\mathrm{CO})$, and, in the presence of elevated $\mathrm{NO}_{\mathrm{x}}$ concentrations, ozone.

Sources of methane are oxygen-deficient wetland habitats such as swamps, lakes, tundra, and boreal marshes. Methane is also produced in soils and oceans, as an end product of the decomposition of organic material. The rate of methane production is highest in tropical wetlands. Methane is also released by anaerobic microbial activity in the stomachs of cattle, termites, and perhaps other insects. Important anthropogenic sources are coal mining, biomass burning, natural gas losses and solid waste burning, as well as cultivation of rice paddies.

Among the most important reasons to measure the concentration of methane is the fact that it is the third most important greenhouse gas in the atmosphere (after water vapour and $\mathrm{CO}_{2}$ ) and that its concentration has almost doubled since preindustrial times, from $0.975 \mathrm{ppmv}$ to $1.85 \mathrm{ppmv}$ (Northern Hemisphere).

On a per molecule basis, methane has a much greater climate warming potential than $\mathrm{CO}_{2}$.

Methane is one of the key target species for the Atmospheric Chemistry Experiment-Fourier Transform Spectrometer (ACE-FTS) instrument that was launched in August 2003. $\mathrm{CH}_{4}$ vertical profiles covering the upper troposphere to mesosphere have been retrieved from the ACE-FTS measurements and need to be validated using independent correlative data, which is the subject of the present paper. More information about the ACE mission and the $\mathrm{CH}_{4}$ retrievals is given in Sect. 2. What we call validation of the ACE-FTS measurements is their comparison with independent data sets that have been characterised earlier and that can therefore be considered reference data sets. The result of such a validation is a characterisation of this new data set relative to known data sets. Similarly, when we use the word bias in the paper, we are talking about a systematic deviation of the ACE-FTS data set relative to the known reference data set.

Available observations of $\mathrm{CH}_{4}$ include the in situ surface networks, in particular, the NOAA/ESRL Global Monitoring Network (http://www.esrl.noaa.gov/gmd/), and the ground-based infrared remote sensing instruments, e.g., in the framework of the Network for Detection of Atmospheric Composition Change (NDACC, http://www.ndacc.org; formerly called NDSC, for Network for the Detection of Stratospheric Change), that have provided long-term systematic high-quality measurements since the early eighties. The former ones provide only local surface data. The latter provide low-resolution vertical profile information and are therefore useful for comparison to the ACE-FTS data, as will be further discussed in Sect. 3.

High vertical resolution profile measurements in the stratosphere and mesosphere, sometimes down to the upper troposphere, have been obtained using satellite-borne limb sounding infrared spectral instruments. Among such earlier satellite experiments is the Atmospheric Trace Molecule Spectroscopy experiment (ATMOS). It is a Fourier-transform solar occultation infrared spectrometer (http://remus.jpl. nasa.gov/atmos) that was deployed four times on the Space Shuttle (April, 1985, March, 1992, April, 1993 and November, 1994), and that can be considered a predecessor of the ACE-FTS instrument (Gunson et al., 1990 and 1996; Abrams et al., 1996). Following ATMOS, observations of $\mathrm{CH}_{4}$ vertical profiles in the stratosphere and upper troposphere have been carried out by the ISAMS (Improved Stratospheric and Mesospheric Sounder) (Remedios et al., 1996), CLAES (Cryogenic Limb Array Etalon Spectrometer) (Roche et al., 1996) and HALOE (Halogen Occultation Experiment) (Russell et al., 1993; Park et al., 1996) instruments onboard UARS, the Upper Atmosphere Research Satellite (http://uars.gsfc.nasa.gov/www root/homepage/uars-science.html; Reber et al., 1993), that operated between mid-September 1991 and mid-December 2005. ISAMS and CLAES stopped observations in July 1992, and May 1993, respectively. HALOE (http:// haloedata.larc.nasa.gov) provides the longest data set, covering the period 11 October 1991 to 21 November 2005, including a significant period of overlap with the ACE mission. HALOE measurements of $\mathrm{CH}_{4}$ have been validated by Park et al. (1996). More information about the quality of the HALOE $\mathrm{CH}_{4}$ data and the comparisons with the ACE-FTS data are given in Sect. 6.

More recently, other interesting global data sets for $\mathrm{CH}_{4}$ are being provided by the SCIAMACHY (SCanning Imaging Absorption spectroMeter for Atmospheric CHartographY) and MIPAS (Michelson Interferometer for Passive Atmospheric Sounding) instruments onboard Envisat (Environmental Satellite) launched on 1 March 2002 (e.g., Frankenberg et al., 2005, and Raspollini, et al., 2006, respectively). However, the actual SCIAMACHY data sets for $\mathrm{CH}_{4}$ provide 
only total column information and therefore this data set is not useful for validation of the ACE-FTS vertical profile measurements. The MIPAS data set and its comparison with ACE-FTS are discussed in Sect. 5.

Presently, observations of tropospheric $\mathrm{CH}_{4}$ are also carried out by AIRS (Atmospheric Infrared Sounder; http:// www-airs.jpl.nasa.gov/; Barnet et al., 2003) onboard Aqua, launched on 4 May 2002, and by TES (Tropospheric Emission Spectrometer; http://tes.jpl.nasa.gov) onboard the AURA satellite, launched on 15 July 2004. At present, TES provides nadir data for $\mathrm{CH}_{4}$ that are not validated yet for geophysical use. The AIRS nadir data for $\mathrm{CH}_{4}$ provide essentially tropospheric column data (up to about $100 \mathrm{hPa}$ ) and therefore are not really suitable for comparison with the ACE-FTS vertical profile data. They provide however a very interesting complementary data set.

Measurements by balloon- and aircraft-borne remote- or in situ-sensing instruments provide information complementary to the satellite and ground-based instruments: in Sect. 4 of the present paper, we show data from the SPIRALE instrument and discuss their agreement with coincident ACE-FTS profiles.

A summary of the above mentioned individual validation efforts is discussed in Sect. 7, in which we also draw clear conclusions regarding the quality of the ACE-FTS $\mathrm{CH}_{4}$ profile data. Once validated, the ACE-FTS $\mathrm{CH}_{4}$ data set will constitute a very valuable extension of the time series made up of the ATMOS, HALOE and MIPAS data, starting in 1985, now covering more than 20 years of high vertical resolution methane distributions from the upper troposphere to the mesosphere on a global scale.

\section{ACE-FTS measurements of $\mathrm{CH}_{4}$}

The ACE-FTS instrument was launched onboard the SCISAT-1 satellite of the Canadian Space Agency, on $13 \mathrm{Au}-$ gust 2003. The satellite is in a high-inclination $\left(74^{\circ}\right)$ circular low-earth orbit $(650 \mathrm{~km}$ from the surface). The ACEFTS operates in solar occultation mode; the orbit provides a latitudinal coverage from $85^{\circ} \mathrm{S}$ to $85^{\circ} \mathrm{N}$ for these measurements. The instrument operates at a high spectral resolution of $0.02 \mathrm{~cm}^{-1}$ in the range of 2.2 to $13.3 \mu \mathrm{m}(750$ $4400 \mathrm{~cm}^{-1}$ ). It provides measurements from the upper troposphere to about $150 \mathrm{~km}$ altitude, of temperature and pressure, of the atmospheric extinction, and of the concentrations of a large number of atmospheric species, with a vertical resolution of the order of $4 \mathrm{~km}$. A description of the ACE mission can be found in Bernath et al. (2005).

Methane $\left(\mathrm{CH}_{4}\right)$ is one of the routinely retrieved target species of ACE-FTS. The retrieval algorithm has been described by Boone et al. (2005). The retrieval process starts with the derivation of pressure and temperature profiles which are then used in the retrieval of the VMR profiles of the atmospheric constituents. The VMR profile above the
Table 1. Microwindows used for the retrieval of $\mathrm{CH}_{4}$ from the ACE-FTS spectra, as a function of retrieval altitude.

\begin{tabular}{|c|c|c|c|}
\hline $\begin{array}{c}\text { Center } \\
\text { Wavenumber } \\
\quad\left(\mathrm{cm}^{-1}\right)\end{array}$ & $\begin{array}{l}\text { Microwindow } \\
\text { Width } \\
\left(\mathrm{cm}^{-1}\right)\end{array}$ & $\begin{array}{c}\text { Lower } \\
\text { Altitude } \\
(\mathrm{km})\end{array}$ & $\begin{array}{c}\text { Upper } \\
\text { Altitude } \\
(\mathrm{km})\end{array}$ \\
\hline 1245.14 & 0.30 & 39 & 50 \\
\hline 1267.78 & 0.30 & 45 & 60 \\
\hline 1270.73 & 0.30 & 40 & 60 \\
\hline 1283.43 & 0.30 & 50 & 70 \\
\hline 1287.80 & 0.30 & 55 & 70 \\
\hline 1299.89 & 0.30 & 40 & 55 \\
\hline 1302.07 & 0.30 & 45 & 70 \\
\hline 1302.74 & 0.30 & 55 & 70 \\
\hline 1303.63 & 0.35 & 45 & 70 \\
\hline 1304.25 & 0.30 & 40 & 60 \\
\hline 1311.50 & 0.30 & 50 & 60 \\
\hline 1322.08 & 0.30 & 38 & 70 \\
\hline 1327.23 & 0.60 & 35 & 70 \\
\hline 1332.08 & 0.30 & 55 & 70 \\
\hline 1332.48 & 0.30 & 40 & 70 \\
\hline 1332.75 & 0.30 & 55 & 70 \\
\hline 1337.55 & 0.30 & 40 & 60 \\
\hline 1341.68 & 0.35 & 35 & 70 \\
\hline 1342.65 & 0.30 & 55 & 70 \\
\hline 1346.65 & 0.40 & 32 & 57 \\
\hline 1348.00 & 0.35 & 32 & 57 \\
\hline 1350.95 & 0.30 & 30 & 55 \\
\hline 1351.74 & 0.30 & 35 & 55 \\
\hline 1353.10 & 0.40 & 33 & 60 \\
\hline 1356.00 & 0.35 & 35 & 55 \\
\hline 1407.60 & 0.30 & 15 & 30 \\
\hline 1427.60 & 0.35 & 9 & 20 \\
\hline 1439.43 & 0.35 & 10 & 25 \\
\hline 1463.00 & 0.35 & 12 & 25 \\
\hline 2610.20 & 0.35 & 10 & 27 \\
\hline 2613.98 & 0.35 & 20 & 30 \\
\hline 2614.73 & 0.30 & 20 & 33 \\
\hline 2618.27 & 0.35 & 25 & 37 \\
\hline 2622.58 & 0.30 & 20 & 33 \\
\hline 2636.30 & 0.30 & 5 & 20 \\
\hline 2644.72 & 0.35 & 12 & 28 \\
\hline 2650.70 & 0.35 & 5 & 20 \\
\hline 2658.08 & 0.35 & 12 & 28 \\
\hline 2658.60 & 0.35 & 5 & 25 \\
\hline 2664.50 & 0.35 & 17 & 30 \\
\hline 2667.19 & 0.30 & 20 & 30 \\
\hline 2667.47 & 0.35 & 10 & 27 \\
\hline 2667.85 & 0.40 & 5 & 25 \\
\hline 2669.65 & 0.30 & 5 & 20 \\
\hline 2671.30 & 0.30 & 15 & 30 \\
\hline 2671.66 & 0.45 & 5 & 25 \\
\hline 2674.15 & 0.35 & 20 & 32 \\
\hline 2675.62 & 0.30 & 12 & 27 \\
\hline 2691.25 & 0.30 & 25 & 35 \\
\hline 2805.97 & 0.30 & 23 & 33 \\
\hline 2809.02 & 0.30 & 27 & 37 \\
\hline 2820.82 & 0.30 & 25 & 40 \\
\hline 2822.68 & 0.30 & 28 & 43 \\
\hline 2825.05 & 0.30 & 28 & 40 \\
\hline 2828.17 & 0.40 & 30 & 45 \\
\hline 2835.61 & 0.35 & 18 & 31 \\
\hline 2839.48 & 0.50 & 8 & 22 \\
\hline 2841.22 & 0.35 & 15 & 30 \\
\hline 2847.72 & 0.35 & 27 & 43 \\
\hline 2849.25 & 0.30 & 25 & 36 \\
\hline 2857.50 & 0.35 & 10 & 25 \\
\hline 2867.10 & 0.30 & 30 & 40 \\
\hline 2869.53 & 0.30 & 5 & 20 \\
\hline 2888.48 & 0.28 & 25 & 39 \\
\hline
\end{tabular}


Table 2. Identification of contributing ground-based FTIR stations.

\begin{tabular}{lrrl}
\hline Site & $\begin{array}{r}\text { Latitude } \\
\text { North }\left(^{\circ}\right)\end{array}$ & $\begin{array}{r}\text { Longitude } \\
\text { East }\left(^{\circ}\right)\end{array}$ & $\begin{array}{l}\text { Responsible } \\
\text { Institution }\end{array}$ \\
\hline Thule & 77 & -69 & NCAR \\
Kiruna & 68 & 20 & IMK-Karlsruhe \\
Poker Flat & 65 & -147 & NICT \\
Jungfraujoch & 47 & 8 & Univ. Liège \\
Toronto & 44 & -79 & Univ. Toronto \\
Izaña & 28 & -16 & IMK-Karlsruhe \\
St. Denis at Ile de La & -21 & 55 & BIRA-IASB \\
Réunion & & & \\
Wollongong & -34 & 151 & Univ. Wollongong \\
Lauder & -45 & 170 & NIWA \\
Arrival Heights & -78 & 167 & NIWA \\
\hline
\end{tabular}

highest analyzed measurement is taken as a constant times the first-guess profile. First-guess profiles for the VMR retrievals are taken from the results of the ATMOS missions (Gunson et al., 1996). It is important to note that ACE-FTS retrievals are not sensitive to a priori information except for the shape of the first-guess profile above the highest analyzed measurement. ACE-FTS forward model calculations employ the HITRAN 2004 line list and cross sections (Rothman et al., 2005). For the retrieval of methane, in the ACE-FTS v2.2 processing, different microwindows have been used, as a function of altitude. They are listed in Table 1. Between 10 and 20 microwindows are used simultaneously at each altitude. The lower altitude limit of a microwindow is chosen to avoid saturation and, in some cases, interferences from other molecules. The upper altitude limit is where the depths of the target absorptions approach the measurement noise. For a molecule like methane it is impossible to use a single set of microwindows over the whole altitude range. In the chosen set of microwindows, there are no strong interferences. Minor interferences from $\mathrm{CH}_{4}$ and $\mathrm{CO}_{2}$ isotopologues $\left({ }^{13} \mathrm{CH}_{4}\right.$, ${ }^{13} \mathrm{CO}_{2}, \mathrm{CO}^{18} \mathrm{O}$ ), and from HDO (for occultations where atmospheric water levels are high) are included in the spectral simulations, but they are so small that there is little benefit in fitting them.

The ACE-FTS retrieved methane VMR profiles extend from the upper troposphere to the lower mesosphere (67 to $70 \mathrm{~km}$ altitude); the reported inversion errors in this altitude range are of the order of a few percent (2 to 3\%), except at the lowest and highest altitude limits of the retrieval where they may rise to more than $10 \%$.

It is worth noticing that in the microwindows used at low altitude, the $\mathrm{CH}_{4}$ lines are affected by line mixing effects and deviate from the Voigt line shape due to collisional effects (Mondelain et al., 2007). These effects are not included in the ACE-FTS forward spectral model, and therefore may contribute to the errors in the retrievals at these altitudes.

\section{Comparisons of ACE-FTS data with FTIR ground- based measurements of $\mathrm{CH}_{4}$}

\subsection{Characteristics of the ground-based FTIR data set}

Ground-based ( $g-b)$ data for methane have been derived from regularly performed solar absorption observations by highspectral-resolution Fourier transform infrared (FTIR) spectrometers, in the framework of NDACC. The names and coordinates of the g-b NDACC stations that have contributed data for the validation of the ACE-FTS methane profiles are listed in Table 2. Good latitudinal coverage is obtained, going from the high Arctic to the Antarctic, including the subtropics. The FTIR data products are profiles with a low vertical resolution, of the order of $10 \mathrm{~km}$, from the surface to an altitude of about $30 \mathrm{~km}$. They are obtained from a spectral fitting procedure using the Optimal Estimation method (Rodgers, 2000), which uses a statistical weighting between a priori information and measurements. More information about the retrieval algorithms can be found in Hase et al. (2004) and references therein. The spectral microwindows, the a priori information and additional retrieval parameters have been optimised at each site as a function of the local conditions (altitude and latitude of the site, spectral data quality, etc.). All microwindows used are situated in the range of 2610 to $2925 \mathrm{~cm}^{-1}$, which coincides with the range in which the microwindows for the ACE-FTS upper troposphere to middle stratosphere $(30 \mathrm{~km})$ retrievals are located - see Table 1. Consistently at all sites, HITRAN2004 spectroscopic parameters and Voigt lineshape functions have been used in the forward line-by-line spectra calculations, as was done for ACE-FTS retrievals. It is important to note that the uncertainties on the spectroscopic parameters of $\mathrm{CH}_{4}$ are rather large, namely of the order of $20 \%$. These uncertainties are a dominant source of systematic uncertainties in the retrieved profiles.

\subsection{Comparison methodology}

For the comparisons, we have required a temporal coincidence within $\pm 24 \mathrm{~h}$, and a spatial coincidence within $\pm 1000 \mathrm{~km}$. These criteria are quite relaxed, but acceptable for a species like $\mathrm{CH}_{4}$ that has a long lifetime and is rather well mixed in the atmosphere. At the polar sites however, the criteria have been more severe. At Arrival Heights, we have used the additional requirement that the difference in potential vorticity (PV) between the observed airmasses (defined at the location of the station and the $30 \mathrm{~km}$ tangent point of the satellite profile) are smaller than $15 \%$. At Kiruna, Thule and Poker Flat, we have required a temporal coincidence within $\pm 12 \mathrm{~h}$, and a spatial coincidence within $\pm 500 \mathrm{~km}$ (for Kiruna and Thule) and within $\pm 600 \mathrm{~km}$ at Poker Flat (with the $\pm 500 \mathrm{~km}$ criterion, we had only 2 coincidences left).

The altitude range in which both instruments have good sensitivity is limited at the lower boundary by the ACE-FTS 
Table 3. Comparisons between ACE-FTS and g-b FTIR partial columns (PC) in the upper troposphere-middle stratosphere at all contributing sites. $\mathrm{N}$ is the number of coincidences (for description of criteria: see text). DOF is the number of Degrees of Freedom for Signal. M is the mean of the differences between the ACE-FTS and g-b FTIR partial columns, in percentage, relative to the mean of the FTIR partial columns; STD is the $1 \sigma$ standard deviation associated with the ensemble of comparisons, and SEM is the associated standard error on the mean, as explained in Sect. 3.2. Err is the combined random error on the difference between the ACE-FTS and FTIR partial columns, in percentage, relative to the mean of the FTIR profiles.

\begin{tabular}{|c|c|c|c|c|c|c|c|}
\hline Site & $\begin{array}{r}\text { ACE-FTS } \\
\text { lower } \\
\text { altitude } \\
(\mathrm{km})\end{array}$ & $\begin{array}{l}\mathrm{PC} \\
\text { limits } \\
(\mathrm{km})\end{array}$ & $\mathrm{N}$ & $\begin{array}{l}\text { DOF for } \\
\text { PC }\end{array}$ & $\mathrm{M} \pm \operatorname{SEM}(\%)$ & $\begin{array}{l}\text { STD } \\
(\%)\end{array}$ & $\begin{array}{l}\text { Err } \\
(\%)\end{array}$ \\
\hline Thule & $7.7 \pm 2.4$ & $12-33$ & 13 & $1.5 \pm 0.0$ & $0.3 \pm 1.5$ & 5.4 & 3.1 \\
\hline Kiruna & $8.9 \pm 1.9$ & $13-26$ & 12 & $1.0 \pm 0.2$ & $3.0 \pm 1.6$ & 5.6 & 2.5 \\
\hline Poker Flat & $7.0 \pm 1.4$ & $11-25$ & 4 & $1.4 \pm 0.2$ & $9.8 \pm 3.5$ & 7.0 & 2.2 \\
\hline Jungfraujoch & $10.1 \pm 3.0$ & $13-25$ & 26 & $0.9 \pm 0.1$ & $0.6 \pm 0.7$ & 3.4 & 2.5 \\
\hline Toronto & $8.2 \pm 2.1$ & $12-32$ & 8 & $1.9 \pm 0.1$ & $-12.1 \pm 2.2$ & 6.0 & 2.5 \\
\hline Izaña & $12.1 \pm 4.1$ & $15-28$ & 5 & $1.1 \pm 0.1$ & $-6.2 \pm 2.9$ & 6.7 & 2.3 \\
\hline St-Denis & $6.8 \pm 1.5$ & $12-29$ & 4 & $0.9 \pm 0.0$ & $-6.1 \pm 1.6$ & 3.3 & 2.6 \\
\hline Wollongong & $6.8 \pm 1.0$ & $12-32$ & 6 & $1.6 \pm 0.1$ & $-4.4 \pm 3.6$ & 8.9 & 3.0 \\
\hline Lauder & $8.1 \pm 2.1$ & $12-30$ & 21 & $1.4 \pm 0.1$ & $-7.8 \pm 1.1$ & 4.7 & 2.6 \\
\hline Arrival Heights & $7.7 \pm 2.0$ & $12-30$ & 19 & $1.3 \pm 0.1$ & $-4.6 \pm 1.1$ & 4.9 & 2.5 \\
\hline
\end{tabular}

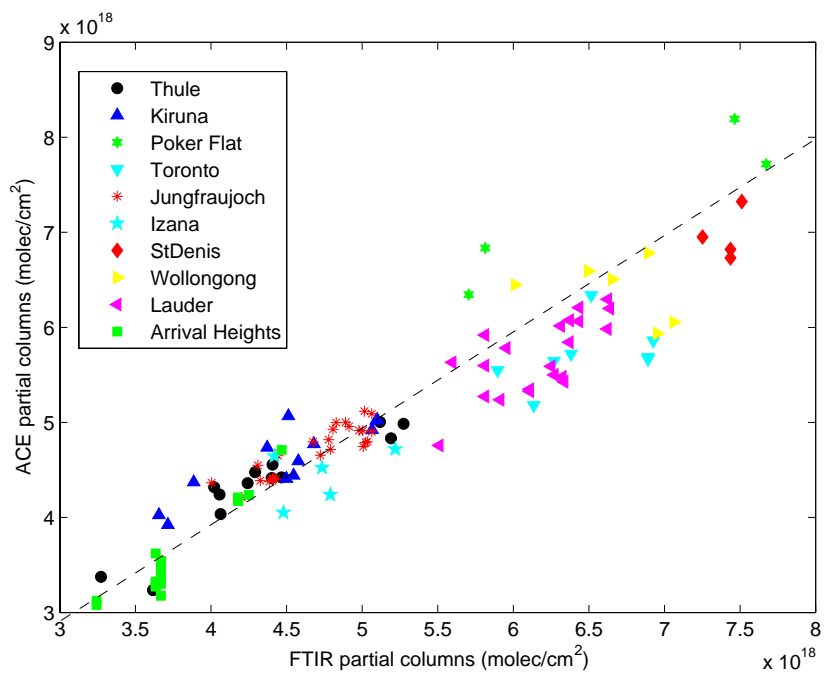

Fig. 1. Correlation plot of the ACE-FTS versus ground-based FTIR partial column amounts of methane considered in the comparisons summarized in Table 3, for all contributing stations. Different symbols refer to different stations, as indicated in the legend.

data and at the upper boundary by the g-b data. We have set the upper altitude as the one for which the $\mathrm{g}$-b data sensitivity reaches $50 \%$. In other words, above that altitude, more than $50 \%$ of the information in the retrieved profiles comes from the a priori information, whereas below that altitude, at least $50 \%$ of the information comes from the FTIR measurement itself. This altitude is close to $30 \mathrm{~km}$. The lowermost altitudes reached by the ACE-FTS profiles vary between 8 and $12 \mathrm{~km}$ above the sites concerned. In this range between 8 to $12 \mathrm{~km}$ and $30 \mathrm{~km}$, the Degrees of Freedom for Signal (DOF) of the g-b FTIR profiles is close to 1 . Therefore we will limit the comparisons to partial columns in the chosen altitude range, and not consider profiles.

Choosing the lower altitude for the partial columns is an exercise in compromise because the lower you fix the partial column lower boundary, the fewer ACE profiles you find that go down to this altitude. We have finally chosen the lower boundary at each site close to $12 \mathrm{~km}$ because this gives us the best compromise between (1) a sufficient number of coincident ACE-FTS in order to have more reliable statistics, and (2), a DOF of the g-b FTIR partial columns in the range above that boundary up to the $50 \%$ sensitivity limit that is close to 1 , and (3), an altitude that is similar at all sites. Izaña was the only site where we had to raise the lower boundary to $14.8 \mathrm{~km}$, because there are only a few coincident profiles (ACE makes fewer observations in the tropics and extratropics than in the polar regions) and only two ACE-FTS profiles that go as low as $12 \mathrm{~km}$. The finally chosen limits are listed in Table 3.

For each ACE-FTS profile, the partial column in the considered altitude range has been compared to the mean of the corresponding ones from the g-b FTIR profiles satisfying the coincidence criteria. To minimize the smoothing error (Rodgers and Connor, 2003), the ACE-FTS profile has first been smoothed with the g-b FTIR averaging kernel (after extrapolating the profile down to the surface using the a priori profile from the $\mathrm{g}-\mathrm{b}$ FTIR retrieval). Figure 1 shows a correlation plot of the considered ACE-FTS versus ground-based FTIR partial column amounts for each contributing station. 
Notice that the variation of the partial column amounts from one station to another is not a pure latitudinal variation: it is also linked to the fact that the altitude limits for the partial columns are not identical for all stations (see Table 3), and that the tropopause heights depend on latitude. In the end, the statistics of the partial column comparisons have been made for each site. These results are given in Table 3, together with some associated relevant information. The mean relative difference between the FTIR and ACE-FTS partial columns has been calculated as $<$ ACE-FTS-FTIR $>/<$ FTIR $>$. In Table 3 , the standard error on the mean relative difference between the FTIR and ACE-FTS partial column (SEM, in percent) has been evaluated as $\mathrm{STD} / \sqrt{ } \mathrm{N}$, in which STD is the statistical 1-sigma $(1 \sigma)$ standard deviation of the observed differences, and $\mathrm{N}$ is the number of coincidences. We will use SEM as a measure of the significance of an observed bias. The combined random error refers to the random error on the difference between the ACE-FTS and g-b FTIR partial columns, derived from the g-b FTIR random error covariance matrix and the ACE-FTS 1-sigma retrieval error provided with each profile (the ACE-FTS error covariance matrix is considered to be diagonal). The combined random error is expressed in percent, relative to the mean of the FTIR partial columns. The g-b FTIR random error covariance matrix has been evaluated for a typical FTIR measurement at Kiruna and has been adopted for all g-b FTIR profiles (F. Hase, private communication). More details about this latter evaluation and the procedure to calculate the random error on the partial column differences can be found in Vigouroux et al. (2007).

\subsection{Comparison results}

Inspection of Table 3 shows that, in the $\mathrm{NH}$, there is a zero or small positive bias of the ACE-FTS partial columns between approximately 12 and $30 \mathrm{~km}$ compared to the g-b FTIR ones, except at Toronto. At the latter station, we see a negative bias of ACE-FTS of the order of $(-12.1 \pm 2.2) \%$; but the number of coincidences, 8 , is rather poor and the g-b FTIR profiles seem to be less constrained (the DOF of the partial columns at Toronto is larger than it is at the other stations). Also at the northern subtropical station of Izaña, we observe a negative bias of ACE-FTS in the lower stratosphere of $(-6 \pm 3) \%$. In the $\mathrm{SH}$, negative biases of ACE-FTS show up at all stations: they are of the order of $-5 \%$ to $-8 \%$. At all sites, we see that the random error on the relative difference is smaller than the observed 1-sigma standard deviation, probably indicating that the coincidence criteria are too weak, and that we are still confronted with the variability in the actual $\mathrm{CH}_{4}$ fields. However, taking into account, on average, the very low number of ACE-FTS overpasses, we have preferred not to strengthen the coincidence criteria.

From the limited number of coincidences, it is not possible given the statistics to draw any conclusion about any seasonal dependence in the differences between the ACE-FTS and g-b FTIR partial columns.

\section{Comparison of ACE-FTS and SPIRALE profiles of $\mathrm{CH}_{4}$}

SPIRALE (French acronym for Spectroscopie Infra-Rouge d'Absorption par Lasers Embarqués) is a balloon-borne instrument operated by LPCE (CNRS-Université d'Orléans) and routinely used at all latitudes, in particular as part of European satellite validation campaigns for Odin and Envisat. The six tunable diode lasers absorption spectrometer (TDLAS) has been described in detail previously (Moreau et al., 2005). In brief it can perform simultaneous in situ measurements of about ten different long-lived and short-lived chemical species from about 10 to $35 \mathrm{~km}$ height, with a high frequency sampling $(\sim 1 \mathrm{~Hz})$, thus enabling a vertical resolution of a few meters depending on the ascent rate of the balloon. The diode lasers emit in the mid-infrared domain (from 3 to $8 \mu \mathrm{m}$ ) with beams injected into a multipass Heriott cell located under the gondola and largely exposed to ambient air. The $3.5 \mathrm{~m}$ long cell is deployed during the ascent when the pressure is lower than $300 \mathrm{hPa}$. The multiple reflections obtained between the two cell mirrors give a total optical path of $430.78 \mathrm{~m}$. Species concentrations are retrieved from direct infrared absorption, by fitting experimental spectra with spectra calculated using the HITRAN 2004 database (Rothman et al., 2005). Specifically, the ro-vibrational line at $1275.3868 \mathrm{~cm}^{-1}$ was used for $\mathrm{CH}_{4}$ (a line not used by ACEFTS). Measurements of pressure (using two calibrated and temperature-regulated capacitance manometers) and temperature (using two probes made of resistive platinum wire) aboard the gondola allow the conversion of the species concentrations into VMRs. Uncertainties in these parameters have been evaluated to be negligible regarding the other uncertainties discussed below. The global uncertainties in the VMRs have been assessed by taking into account the random errors and the systematic errors, and combining them as the square root of their quadratic sum. The random errors (fluctuations of the laser background emission signal and signalto-noise ratio) and the systematic errors (laser line width and non-linearity of the detector) are very low, resulting in an estimated global uncertainty of $5 \%$ for $\mathrm{CH}_{4}$, over the whole altitude range.

The SPIRALE measurements occurred on 20 January 2006, between 17:46 UT and 19:47 UT, with vertical profiles obtained during ascent, between 13.2 and $27.3 \mathrm{~km}$ height. The measurement position remained rather constant, at the balloon mean location of $67.6 \pm 0.2^{\circ} \mathrm{N}$ and $21.55 \pm 0.20^{\circ} \mathrm{E}$. The comparison is made with the v2.2 data from the ACEFTS sunrise sr13151 occultation that occurred $13 \mathrm{~h}$ later (on 21 January 2006 at $08: 00 \mathrm{UT}$ ) and was located at $64.28^{\circ} \mathrm{N}$, $21.56^{\circ}$ E, i.e., $413 \mathrm{~km}$ away from the SPIRALE position. Using the MIMOSA contour advection model (Hauchecorne et al., 2002), PV maps in the region of both measurements have been calculated for each hour between 17:00 UT on 20 January and 08:00 UT on 21 January on isentropic surfaces, every $50 \mathrm{~K}$ from $400 \mathrm{~K}$ to $800 \mathrm{~K}$ (corresponding to $16-30 \mathrm{~km}$ 
height). From these it was concluded that SPIRALE and ACE-FTS sounded similar air masses in the well-established polar vortex for the whole range of altitudes. The dynamical situation was very stable with a PV agreement better than $10 \%$. So the geophysical situation was suitable for direct comparisons. In order to compare ACE-FTS and SPIRALE the difference in the vertical resolution of these two instruments had to be taken into account. Indeed, ACE-FTS has a vertical resolution of 3-4 km and that of SPIRALE is on the order of meters. A triangular convolution function of $3 \mathrm{~km}$ at the base (corresponding to the ACE-FTS vertical resolution) has been applied to the SPIRALE data. Consequently, the bottom and the top of SPIRALE profile have been truncated by $1.5 \mathrm{~km}$. Then an interpolation onto the ACE-FTS 1 $\mathrm{km}$-grid was performed.

Figure 2 shows that the ACE-FTS and SPIRALE $\mathrm{CH}_{4}$ profiles are in good agreement below $24 \mathrm{~km}$ even if error bars do not overlap at the lowest altitudes (below $19 \mathrm{~km}$ ). The observed relative differences over the altitude range of 15 to $24 \mathrm{~km}$ are smaller than $10 \%$, with ACE-FTS values larger than SPIRALE except at $22.5 \mathrm{~km}$. Above $24 \mathrm{~km}$ the relative differences increase, reaching $37 \%$ at $25.5 \mathrm{~km}$, with ACEFTS giving larger values than SPIRALE.

\section{Comparisons between ACE-FTS and correlative MI- $\mathrm{PAS} \mathrm{CH}_{4}$ profiles}

The Michelson Interferometer for Passive Atmospheric Sounding (MIPAS) is an infrared limb-sounding Fourier transform interferometer on board the Envisat satellite, launched in March 2002 (Fischer et al., 2007). It acquires spectra over the range $685-2410 \mathrm{~cm}^{-1}(14.5-4.1 \mu \mathrm{m})$, which includes the vibration-rotation bands of many molecules of interest. It is capable of measuring continuously around each orbit during both day and night, and complete global coverage is obtained within $24 \mathrm{~h}$.

From July 2002 until March 2004, MIPAS was operated at full spectral resolution $\left(0.025 \mathrm{~cm}^{-1}\right)$ with a nominal limb-scanning sequence of 17 steps from 68 to $6 \mathrm{~km}$ with $3 \mathrm{~km}$ tangent height spacing in the troposphere and stratosphere, generating complete profiles spaced approximately every $500 \mathrm{~km}$ along the orbit. However, in March 2004 operations were suspended following problems with the interferometer slide mechanism. Operations were resumed in January 2005 with a $35 \%$ duty cycle and reduced spectral resolution $\left(0.0625 \mathrm{~cm}^{-1}\right)$.

For the high-resolution part of the mission ESA has processed PT (pressure-temperature) and six "key species" $\left(\mathrm{H}_{2} \mathrm{O}, \mathrm{O}_{3}, \mathrm{HNO}_{3}, \mathrm{CH}_{4}, \mathrm{~N}_{2} \mathrm{O}\right.$ and $\left.\mathrm{NO}_{2}\right)$. The algorithm used for the Level 2 analysis is based on the Optimised Retrieval Model (ORM) (Raspollini et al., 2006; Ridolfi et al., 2000). The spectroscopic database used in this retrieval is the so-called mipas_pf3.1 database (Flaud et al., 2003) which contains the same $\mathrm{CH}_{4}$ line parameters as HITRAN 2004
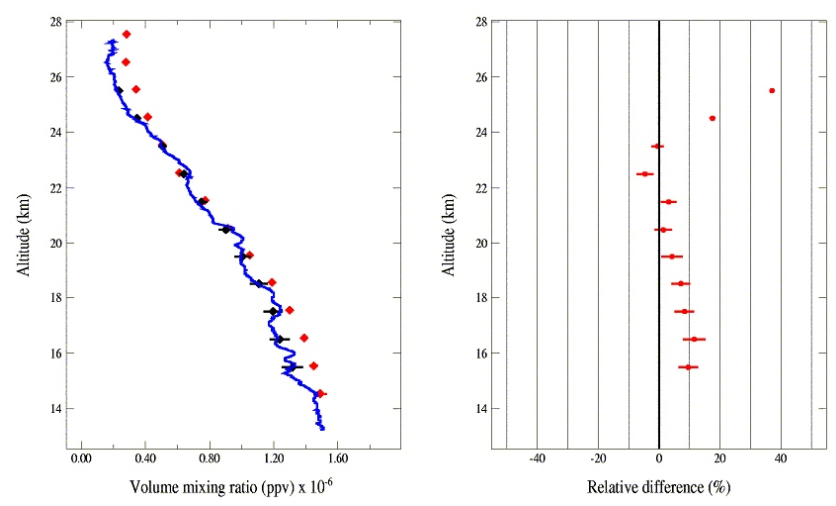

Fig. 2. Left plot: Methane vertical profiles obtained by ACE-FTS sr13151 (in red) and SPIRALE (in black and blue). The solid blue line corresponds to the SPIRALE measurements (very fine resolution) and the black diamonds correspond to the SPIRALE profile smoothed with a triangular convolution function (see Sect. 4). Error bars are reported on both profiles but, at several altitudes, they are so small that they are indiscernible. Right plot: The relative differences between the two profiles in percent, calculated as (200*(ACESPIRALE)/(ACE + SPIRALE) ) and the corresponding error bars.

in the microwindows used by MIPAS. These windows are $1227.1750-1230.1750 \mathrm{~cm}^{-1}$ in the 6 to $60 \mathrm{~km}$ altitude range, and $1350.8750-1353.8750 \mathrm{~cm}^{-1}$ in the 12 to $68 \mathrm{~km}$ altitude range. The validation of the MIPAS operational v4.62 data processed by ESA is near completion (Espy and Hartogh, 2006; Piccolo and Dudhia, 2007), including a paper describing validation of $\mathrm{CH}_{4}$ (Payan et al., 2007). The latter paper concludes, in part from comparisons with g-b FTIR data and HALOE profiles, that MIPAS overestimates the methane concentrations in the pressure range of 140 to $0.3 \mathrm{hPa}(\sim 15$ to $58 \mathrm{~km}$ ): on the global scale, the bias is of the order of 5 to $20 \%$. The comparisons with HALOE show that the bias is largest at the upper and lower ends of the profiles. The observed biases with HALOE are however within the estimated combined systematic uncertainties, except at the highest altitudes (pressure $<0.5 \mathrm{hPa}$ ).

In the present paper, MIPAS methane data v4.62 are compared with ACE-FTS version 2.2 data for the period from 21 February 2004 to 26 March 2004. During the first five months of the ACE mission, only sunsets were measured because of problems with spacecraft pointing at sunrise; therefore only $\mathrm{NH}$ data are available. The selected coincidence criteria were a maximum spatial and temporal difference of $300 \mathrm{~km}$ and $6 \mathrm{~h}$, respectively. This slightly relaxed temporal mismatch $(6 \mathrm{~h})$ has been chosen in order to increase the statistics of the comparison, knowing that the species variability does not vary significantly when going from 3 to $6 \mathrm{~h}$ mismatch. So finally, the latitudinal coverage of the comparisons turns out to be limited to $70^{\circ} \mathrm{N}-80^{\circ} \mathrm{N}$.

The comparison has been done including all the matching pairs (131) of measurements available in the considered 


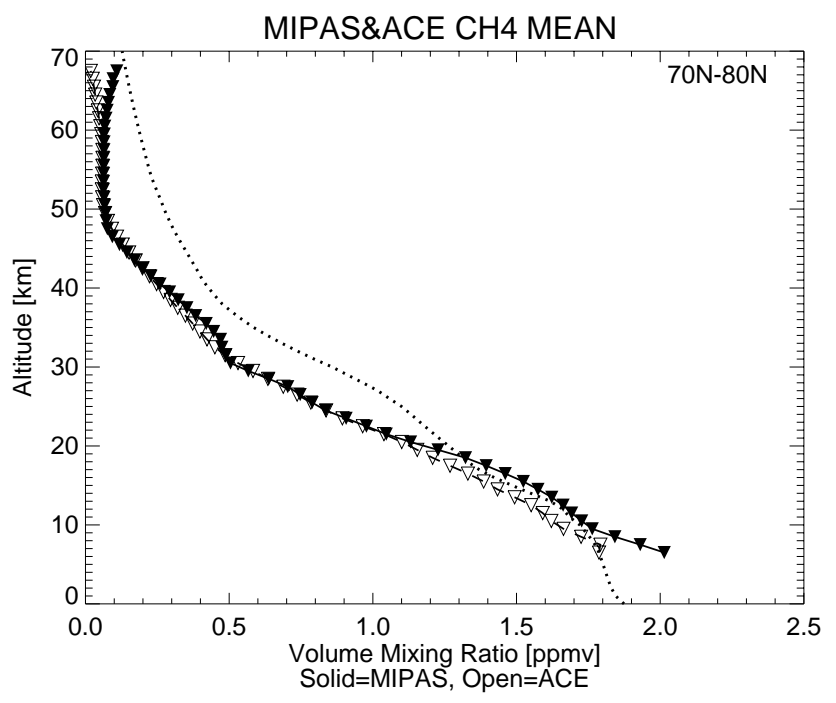

Fig. 3. Mean ACE-FTS (open triangles) and MIPAS (filled triangles) profiles of the 131 matching pairs in the $70-80^{\circ} \mathrm{N}$ latitude band, included in the comparison. The dotted line shows the MIPAS climatology (initial guess) for this latitude band.

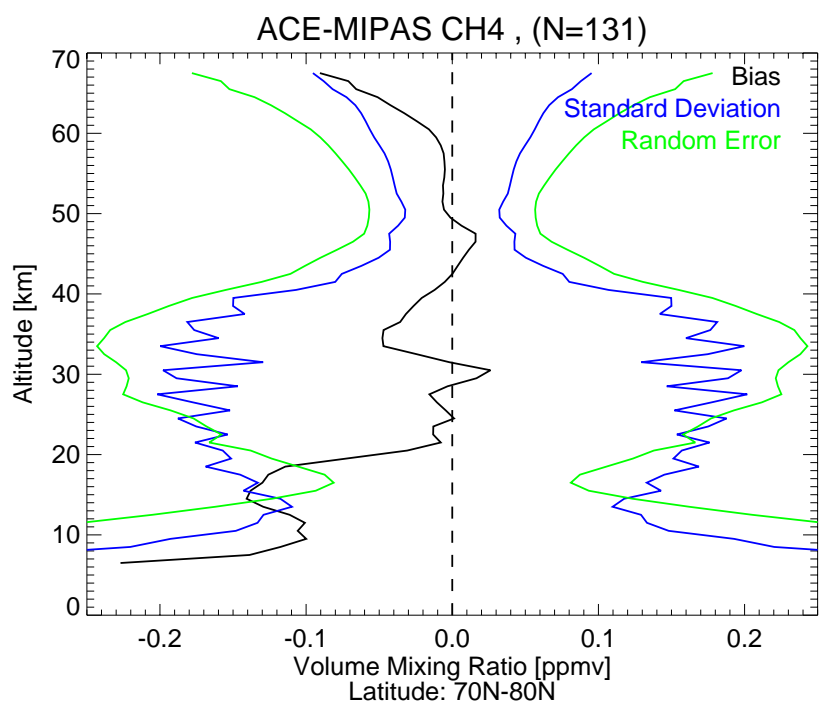

Fig. 4. VMR difference between ACE-FTS and MIPAS profiles of $\mathrm{CH}_{4}$ : mean ACE-FTS minus MIPAS (black solid line) and associated $1 \sigma$ standard deviation (blue solid line) for a sample of 131 coincident profiles in the 70 to $80^{\circ} \mathrm{N}$ latitude band. The random error of the difference profile, combining the MIPAS and ACE-FTS random errors, is shown as the green solid line.

period. Only the successfully retrieved points of the ACEFTS profiles have been used in the comparison. Because the ACE-FTS profile above the highest analysed measurement is given as a scaled initial guess profile, it is not taken into account in the comparison. For MIPAS, only profiles associated with successful pressure/temperature and target species retrievals have been considered. It is useful to note that in

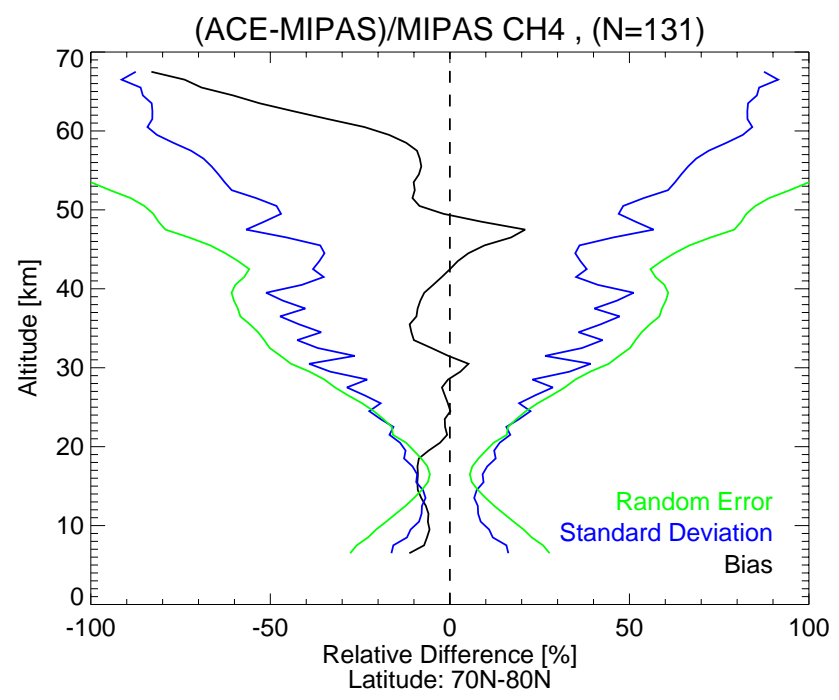

Fig. 5. Percentage relative difference between ACE-FTS and MIPAS profiles of $\mathrm{CH}_{4}$ : mean ACE-FTS minus MIPAS divided by MIPAS ( black solid line) and associated standard deviation (blue solid line) for a sample of 131 coincident profiles in the 70 to $80^{\circ} \mathrm{N}$ latitude and ACE-FTS errors, is shown as the green solid line.

the operational MIPAS data negative VMR values have been truncated to $1.0 \times 10^{-10}$. These values have been filtered out from the profiles before making the comparison.

As far as MIPAS errors are concerned, we refer, in general, to the ESA level 2 products for the random error due to propagation of the instrument noise through the retrieval (Piccolo and Dudhia, 2007) and to results of the analysis carried out at University of Oxford for the systematic error (see data available at http://www-atm.physics.ox.ac.uk/group/mipas/err). Some of the components, listed in the Oxford University data set as systematic error on the individual profiles, show a random variability over the longer time-scale involved when averaging different MIPAS scans and/or orbits and tend to contribute to the standard deviation of the mean difference rather than to the bias. Taking this into account, for the present comparison with ACE-FTS, we have considered the error contribution due to propagation of pressure and temperature random covariance into the retrieval of key species VMR (taken from the Oxford Univ. data set) as a randomly variable component and combined it with the measurement noise - using the root-sums-square method - to obtain MIPAS random error.

Figures 3 to 5 show the comparison results on a statistical basis. Figure 3 includes the MIPAS climatological profile for the considered latitude band as a reference: this profile is taken from the MIPAS IG2 (initial guess) seasonal climatology by Remedios et al. $(1999,2007)$, and has been used in the ESA MIPAS data processing in the construction of the initial guess profile (Raspollini et al., 2006). From the mean of the 131 matching pairs of ACE-FTS and MIPAS profiles 
between 10 and $70 \mathrm{~km}$ altitude shown in Fig. 3, one sees immediately a very good agreement at all altitudes, except below $21 \mathrm{~km}$, between 32 and $40 \mathrm{~km}$, and above $60 \mathrm{~km}$. The differences ACE-FTS minus MIPAS are shown quantitatively in Figs. 4 and 5, in absolute units and percentages relative to MIPAS, respectively. Up to $60 \mathrm{~km}$, the agreement looks very good, with relative differences that are within $\pm 12 \%$ except around $47 \mathrm{~km}$ where it rises to about $20 \%$. If we consider the standard errors on the mean, defined as $\sigma / \sqrt{ } \mathrm{N}$ with $\sigma$ the standard deviation and $\mathrm{N}$ the number of coincidences (131), as a measure of the significance of the bias, we find statistically significant negative biases between 8 and $20 \mathrm{~km}$, of the order of $-10 \% \pm 1.5 \%$, and between 32 and $40 \mathrm{~km}$, of the order of $-10 \% \pm 5 \%$. We find a statistically significant positive bias of about $19 \% \pm 5 \%$ around $46-47 \mathrm{~km}$. Above $50 \mathrm{~km}$ the bias becomes negative again, of order $-10 \% \pm 6 \%$, and rises drastically above $60 \mathrm{~km}$, up to $-80 \% \pm 8 \%$. It has been verified that this large bias above $60 \mathrm{~km}$ is not due to the different sensitivity of MIPAS and ACE-FTS to non-local thermodynamic equilibrium (NLTE) conditions. Indeed, the emissions used in the MIPAS retrievals in the $v_{4}$ band near $7.6 \mu \mathrm{m}$ are in NLTE conditions during daytime above $50 \mathrm{~km}$, reaching limb radiance deviations larger than $20 \%$ at $60 \mathrm{~km}$ and up to $60 \%$ at $70 \mathrm{~km}$ (López-Puertas et al., 2005), whereas the ACE-FTS absorptions are free of NLTE. But separate dayand nighttime comparisons show no significant differences as to the observed bias above $60 \mathrm{~km}$. Above $60 \mathrm{~km}$ however, the random error on the MIPAS $\mathrm{CH}_{4}$ profiles grows very large (from 10 to 60\%) (Fig. 5 in Raspollini et al., 2006). The biases look compatible with the systematic uncertainty on the MIPAS profiles due to spectral database errors (Fig. 5 in Raspollini et al., 2006) that is of the same order of magnitude. Another reason for the high bias might be the truncation of negative VMR values in the operational MIPAS data that was mentioned above.

We also see that the standard deviation of the comparison is always smaller than the combined random error, as it should be, except in the range of 15 to $22 \mathrm{~km}$ altitude. This may be an indication of the fact that the variability in this altitude range in the dataset corresponds to high latitude northern winter-spring conditions, and is therefore too large within the chosen coincidence criteria.

\section{Comparisons between ACE-FTS and correlative HALOE $\mathrm{CH}_{4}$ profiles}

\subsection{Statistical analyses}

A statistical analysis was performed to compare v2.2 $\mathrm{CH}_{4}$ profiles from the ACE-FTS to v19 retrievals from HALOE onboard UARS. Like the ACE-FTS, HALOE is a solar occultation instrument, but the inclination of its orbit is $57^{\circ}$. Unlike ACE-FTS, HALOE is a filter channel spectrometer, that uses a gas filter correlation technique in the $3.3 \mu \mathrm{m}$ re-

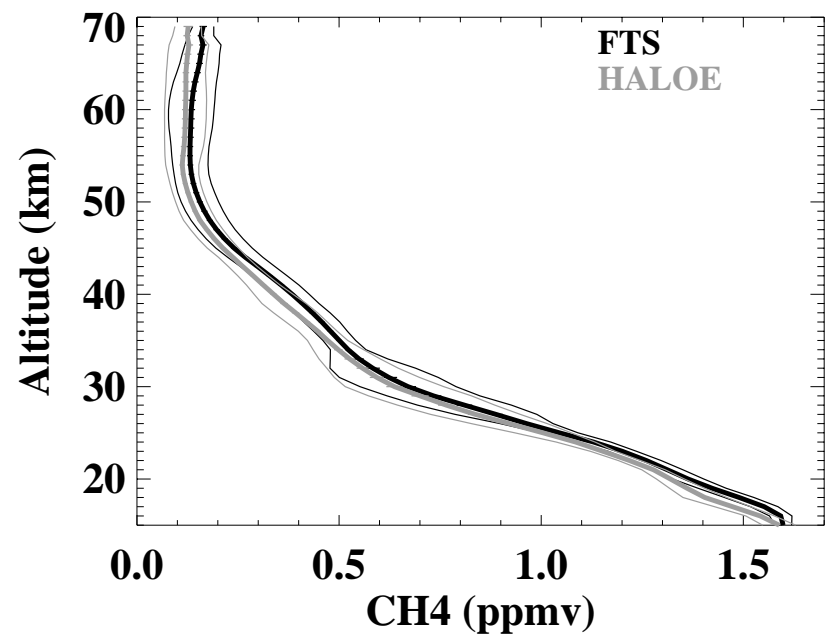

Fig. 6. Average profiles (thick lines) for all coincident measurements between ACE-FTS (black) and HALOE (gray). Thin lines are the profiles of standard deviations $(1 \sigma)$ of the distributions, while error bars (often too small to be seen) represent the uncertainty in the mean ( $\sigma$ divided by the square root of the number of comparisons).

gion (Russell et al., 1993). HALOE ceased operations in November 2005, so it operated throughout most of the first

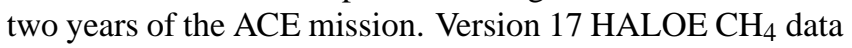
were found to agree with correlative measurements to within about $15 \%$ in the stratosphere (Park et al., 1996). Comparisons between v19 HALOE and v1.0 ACE-FTS data were described by McHugh et al. (2005), who found that ACEFTS $\mathrm{CH}_{4}$ was about $10 \%$ higher than HALOE in the 18 to $55 \mathrm{~km}$ altitude range.

The HALOE and ACE-FTS v2.2 data sets were searched for coincident measurements, defined as occurring within $2 \mathrm{~h}$ in time and $500 \mathrm{~km}$. ACE-FTS profiles with error bars larger than $100 \%$ have been discarded. A total of 36 coincidences were found; 5 of these corresponded to satellite sunrise (SR) occultations in both instruments, while the other 31 corresponded to satellite sunset (SS) occultations in both instruments. Opening up the time criterion to one day did not result in any new coincidences. The SS coincidences occurred from 4-10 July 2004 ( 29 coincidences, average latitude $66^{\circ} \mathrm{N}$ ) and 15 August 2005 ( 2 coincidences, average latitude $49^{\circ} \mathrm{S}$ ); the SR coincidences occurred on 6-7 September 2004 (5 coincidences, average latitude $60^{\circ} \mathrm{N}$ ). Thus the majority of the comparisons correspond to polar summer conditions in the $\mathrm{NH}$.

Figure 6 shows the average $\mathrm{CH}_{4}$ profiles measured by both instruments for all coincidences. Although the analysis was performed separately for sunrise and sunset occultations, there were too few sunrise coincidences to obtain statistically significant results. Thus, only results for averages over all of the coincidences are reported here. Both instruments show very similar profile shapes, with the ACE-FTS mixing ratios 


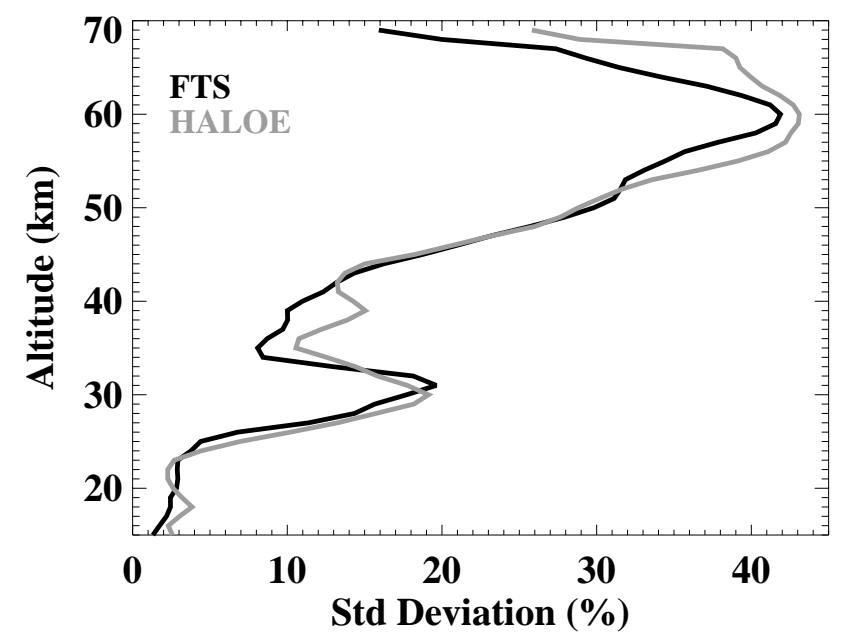

Fig. 7. Standard deviations of the distributions, $1 \sigma$, relative to the mean $\mathrm{CH}_{4}$ mixing ratio at each altitude, for all coincident events, for ACE-FTS (black) and HALOE (gray).

biased slightly high compared to HALOE, particularly above $35 \mathrm{~km}$ and below $25 \mathrm{~km}$. At many altitudes the differences are accompanied by nearly overlapping error bars, suggesting that the differences are insignificant. Thin lines in Fig. 6 represent the standard deviations of the distribution of profiles measured by each instrument. Qualitatively, it is clear that both instruments measure similar variability.

Measurement variability is quantified more clearly in Fig. 7, which shows the standard deviations of the distributions relative to the mean mixing ratios. There is excellent agreement between ACE-FTS and HALOE at all altitudes, with both instruments capturing the local minimum in variability near $35 \mathrm{~km}$, and maxima near 30 and $60 \mathrm{~km}$. Hoppel et al. (1999) have shown evidence for summertime longitudinal variations in ozone from $21-28 \mathrm{~km}$, at latitudes similar to those of the coincidences analyzed here. These variations arise from differential meridional transport caused by breaking of westward-propagating waves that are evanescent in the summer easterly flow. It is likely that this transport would also result in longitudinal variations in $\mathrm{CH}_{4}$, thereby explaining the $30-\mathrm{km}$ maximum in variability measured by both HALOE and ACE-FTS. A similar increase in variability is seen in the ACE-FTS HF and $\mathrm{H}_{2} \mathrm{O}$ comparisons with HALOE (E. Mahieu and M. Carleer, respectively, private communication). Another contribution to the high variability at $30 \mathrm{~km}$ may be the chemical conversion between $\mathrm{H}_{2} \mathrm{O}$ and $\mathrm{CH}_{4}$ : Nassar et al. (2005) noted that the variability in either $\mathrm{CH}_{4}$ or $\mathrm{H}_{2} \mathrm{O}$ was higher than the variability in $\left[\mathrm{H}_{2} \mathrm{O}\right]+2\left[\mathrm{CH}_{4}\right]$.

Figure 8 shows the percent differences between the instruments, plotted as ACE-FTS minus HALOE relative to the average of the two instruments. As noted above, measurements from ACE-FTS are biased high compared to HALOE, with largest differences above $35 \mathrm{~km}$. The overall agreement,

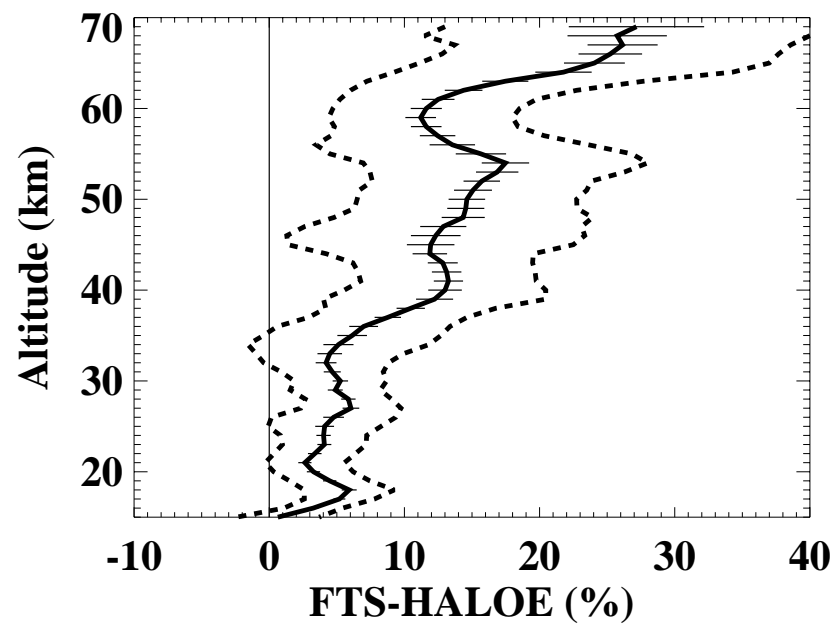

Fig. 8. Average percent differences (solid) between ACE-FTS and HALOE relative to the average of the two instruments, for all coincidences. Dashed lines represent the $1 \sigma$ standard deviation of the distribution of differences while the error bars represent the uncertainty in the mean difference, i.e., $\sigma / \sqrt{ } \mathrm{N}$ where $\mathrm{N}$ is the number of coincidences.

however, is excellent, with differences between the two instruments on the order of only $5 \%$ below $35 \mathrm{~km}$, increasing to about $10-15 \%$ from $40-60 \mathrm{~km}$. Overall, these results confirm that the ACE-FTS $\mathrm{CH}_{4}$ measurements are on a par with the HALOE data, which have been used extensively for scientific analyses.

\subsection{Comparisons in equivalent latitude/potential tempera- ture space}

ACE-FTS and HALOE $\mathrm{CH}_{4}$ are compared here by mapping both fields in equivalent latitude $(\mathrm{EqL}) /$ potential temperature $(\theta)$ coordinates. The ACE and HALOE "Derived Meteorological Products" (DMPs) from the Met Office assimilated meteorological analyses are used to provide $\mathrm{EqL} / \theta$; these, and the mapping versus EqL, are described in detail by Manney et al. (2007). The mapping in EqL/ $\theta$ is done as described by Manney et al. $(1999,2001)$ by taking weighted averages of the measurements around each EqL/ $\theta$ gridpoint; in addition to being weighted by the "distance" (in EqL, $\theta$ ) from the gridpoint, the average is weighted by the uncertainty value associated with the measurement point. The EqL grid spacing used is $5^{\circ}$, and the $\theta$ grid spacing corresponds to a 3$\mathrm{km}$ grid, comparable to the vertical resolution of ACE-FTS and $\mathrm{HALOE} \mathrm{CH}_{4}$ profiles. EqL/time plots are produced in the same way, but gridding in time instead of $\theta$. Time grid points are at 12:00 UT each day. The use of EqL as a coordinate allows us to compare measurements that are not spatially coincident, but were measured in the same air mass. Manney et al. (2007) showed that using EqL mapping to compare long-lived trace gases (such as $\mathrm{CH}_{4}$ ) minimizes most biases 
related to sampling differences in the EqL regions that are covered by both instruments.

Figure 9 shows the time evolution of ACE-FTS and HALOE $\mathrm{CH}_{4}$ at $850 \mathrm{~K}(\sim 10 \mathrm{hPa}$ or $30 \mathrm{~km})$ in the middle stratosphere from November 2004 through October 2005. The overlaid PV contours show the evolution of the polar vortices (solid contours are in vortex edge region). Because of the asymmetry and variability of the winter polar vortices, ACE-FTS measurements provide extensive coverage of conditions in and around the polar vortices. Very low $\mathrm{CH}_{4}$ values in the vortices and very strong gradients across the vortex edge are the signature of strong, confined descent in the vortex (Schoeberl, et al., 1992 and references therein; Schoeberl et al., 1995; Manney et al., 1999); the close correspondence of the strong $\mathrm{CH}_{4}$ gradient region in ACE-FTS with the evolution and position of the vortex-edge PV contours indicates good consistency of the ACE-FTS data with the meteorological fields.

ACE-FTS and HALOE measurements are rarely closely coincident in space and time. The general features of the evolution shown in Fig. 9 do, however, suggest good agreement in the overall time evolution of $\mathrm{CH}_{4}$ from the two instruments, for example, the consistency in values, gradients and time changes along the Arctic vortex edge in November through March, similar high latitude values in summer in both hemispheres and in the equatorial regions. While close physical coincidences are few, during a typical month, HALOE and ACE-FTS cover many of the same EqL regions, indicating sampling of similar air masses. Figure 10 takes advantage of this for a more detailed comparison of ACEFTS and HALOE, showing EqL/ $\theta$ plots gridded as described above using all data from a month for November 2004, January 2005, June 2005, and September 2005. The signature of strong descent in the polar vortex is again apparent in ACEFTS data for September in the SH, and in January in the NH; the NH November ACE-FTS fields show that much of the descent in the vortex region has already occurred by then, consistent with, e.g., Manney, et al. (2000). In November, the SH signature of strong descent is still apparent, but in the middle to upper stratosphere, strong mixing as the vortex breaks up has transported high $\mathrm{CH}_{4}$ to high $\mathrm{SH}$ latitudes, while the lower stratospheric vortex is still strong; this pattern is consistent with that seen in MLS observations of $\mathrm{N}_{2} \mathrm{O}$ and $\mathrm{H}_{2} \mathrm{O}$ at this time (Manney et al., 2005). Differences between HALOE and ACE-FTS in regions of common coverage show good agreement in all periods shown. In November 2004 and January 2005 , maximum differences are $\sim 0.2$ ppmv, and primarily localized, with no clear evidence of a consistent bias, other than a possible high bias of ACE-FTS with respect to HALOE of up to about $15 \%$ in January in the SH above $\sim 1000 \mathrm{~K}(\sim 35 \mathrm{~km})$, and a slight low bias of ACE-FTS with respect to HALOE near $60^{\circ} \mathrm{EqL}$ above $700 \mathrm{~K}(\sim 30 \mathrm{~km})$. Results for June are similar, except for a larger high ACEFTS bias in the small EqL-coincident region in the $\mathrm{NH}$ upper stratosphere. There is also a slight low bias of ACE-FTS

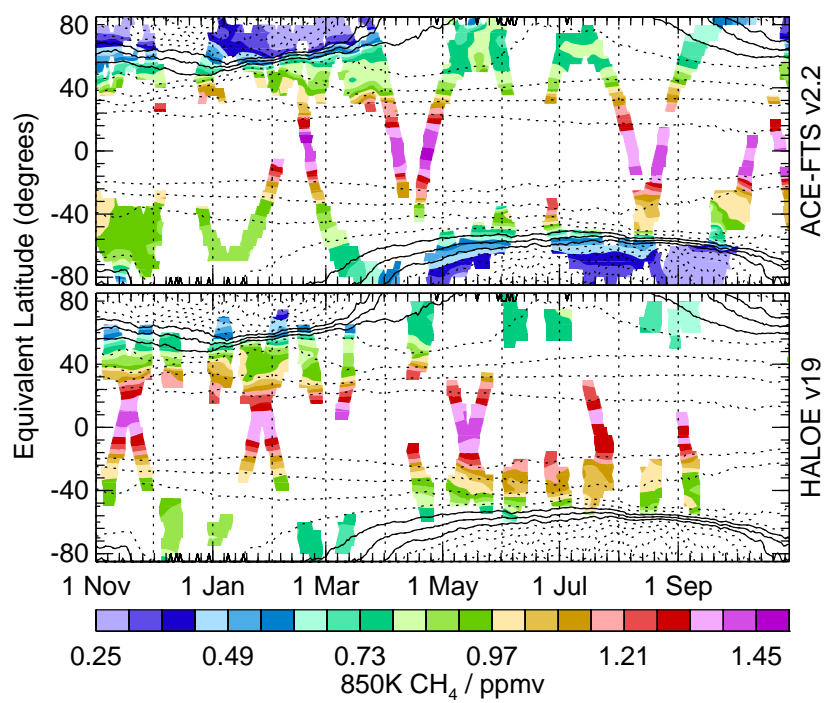

Fig. 9. ACE-FTS (top) and HALOE (bottom) CH4 VMR (ppmv) on the $850 \mathrm{~K}$ potential temperature surface as a function of equivalent latitude and time (see text) for November 2004 through October 2005. Overlaid contours are scaled PV from the Met Office meteorological analyses, with solid line showing contours demarking the polar vortex edge region.

with respect to HALOE above $700 \mathrm{~K}$ near $-60^{\circ} \mathrm{EqL}$, similar to that seen in the NH in January. These slight low ACE-FTS biases are along the vortex edge, and may thus be related to sampling effects, since in that region of very strong gradients, non-uniform sampling at different geographical latitudes may still affect EqL/ $\theta$ results (Manney et al, 2007). The September results show slightly larger differences, with up to an $\sim 25 \%$ high bias (still only $\sim 0.2 \mathrm{ppmv}$ ) in much of the upper stratosphere, especially in the SH equatorward of $-40^{\circ}$ EqL. A slight high bias in the NH upper stratosphere is consistent with the analysis shown above in Sect. 6.1 of spatially coincident ACE-FTS and HALOE measurements. None of those coincidences were in the $\mathrm{NH}$ fall and winter periods represented by the November and January plots shown here, and the lack of a clear bias in these plots suggests that the HALOE/ACE-FTS differences may be seasonally-dependent and thus possibly related to atmospheric variability.

\subsection{Consistency between both approaches}

As pointed out above, one sees similar biases in summer high $\mathrm{NH}$ latitudes in both the $(\mathrm{EqL} / \theta)$ (Sect. 6.2) and the statistical approach based on geographical coincidences (Sect. 6.1). It has been verified that the results of the statistical approach are robust with respect to $\mathrm{EqL}$ criteria.

The $(\mathrm{EqL} / \theta)$ approach has a better global coverage in space and time, but it has the disadvantage that it is very difficult to identify whether an observed difference is statistically significant or not. The reason is that the value in a gridbox is derived from a different number of observations, and each of 

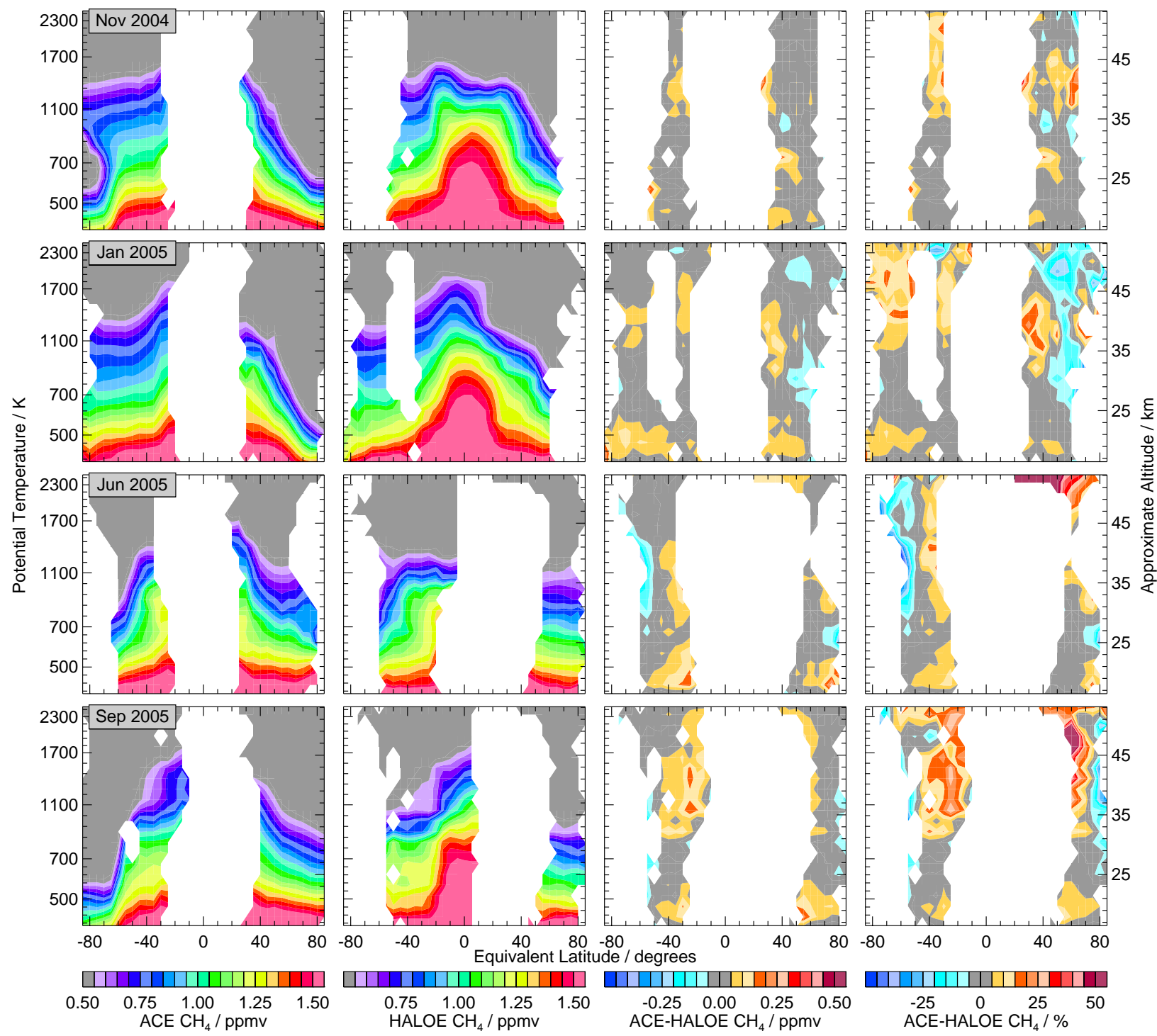

Fig. 10. Equivalent latitude/potential temperature (see text) sections of (left to right) ACE-FTS $\mathrm{CH}_{4}, \mathrm{HALOE} \mathrm{CH}_{4}, \mathrm{ACE}^{-\mathrm{FTS}}-\mathrm{HALOE}$ $\mathrm{CH}_{4}$ in ppmv, and ACE-FTS-HALOE $\mathrm{CH}_{4}$ in percent, for the months (from top to bottom) November 2004, January, June and September 2005. Vertical range is $400 \mathrm{~K}$ to $2500 \mathrm{~K}$ (15 to $50 \mathrm{~km})$.

those is weighted differently according to its distance from the center of the gridbox and according to the uncertainties reported in the data files. So it is almost impossible to give a value above which the differences are significant. Because of this, $(\mathrm{EqL} / \theta)$ mapping never provides a fully quantitative comparison.

Nevertheless, in the present study, it provides an indication of an ACE-FTS bias that has a latitudinal and seasonal dependence, and shows that in almost all cases, biases relative to HALOE are smaller than $25 \%$ in absolute value, leading to the conclusion that ACE-FTS and HALOE measurements of methane in the stratosphere-lower mesosphere are in good agreement.

\section{Conclusions}

\subsection{Northern Hemisphere (NH)}

In the high latitude $\mathrm{NH}$, we have many comparisons in winter-spring namely one with a single SPIRALE profile in polar vortex conditions $\left(67^{\circ} \mathrm{N}\right.$, January 2006$)$, a statistical set of 131 MIPAS and ACE-FTS matched profiles in the $70-80^{\circ} \mathrm{N}$ latitude range between 21 February and 26 March 2004 , and HALOE comparisons in $(\mathrm{EqL} / \theta)$ space. We also have year-round comparisons with three ground-based stations. The results of these comparisons indicate that the ACE-FTS $\mathrm{CH}_{4}$ VMR profiles are biased negative (of the order of $-10 \%$ ) with respect to MIPAS in the 8 to $20 \mathrm{~km}$ 
altitude range, but positive $(+10 \%)$ with respect to SPIRALE in a similar (15 to $20 \mathrm{~km}$ ) altitude range. The comparisons of partial columns in the 12 to $25 \mathrm{~km}$ altitude range at the three high latitude ground-based stations also show a zero or slightly positive bias of the same order of magnitude. The comparisons with MIPAS and g-b FTIR seem to be consistent with the observation from Payan et al. (2007), mentioned in Sect. 5, that MIPAS has a high bias in this altitude range of the order of 5 to $20 \%$.

At higher altitudes (stratosphere and lower mesosphere, up to $60 \mathrm{~km}$ ), ACE-FTS $\mathrm{CH}_{4}$ VMR profiles are in very good agreement with MIPAS. Above $60 \mathrm{~km}$, the negative bias of ACE-FTS relative to MIPAS grows to $-20 \%$, but the errors on the individual MIPAS and ACE-FTS profiles become very high (larger than $30 \%$ for MIPAS).

The comparisons with HALOE do not cover the lowest altitude range, nor do they cover well the $\mathrm{NH}$ winter high latitude regions. But in NH high latitude summer conditions, comparisons with HALOE indicate that ACE-FTS has a positive bias of the order of 5 to $15 \%$ in the stratosphere, below and above $35 \mathrm{~km}$, respectively. The bias rises to $+30 \%$ above $65 \mathrm{~km}$. If we presume that there is no seasonal variation in the bias in the high latitude $\mathrm{NH}$, then this is consistent with the good agreement observed between ACE-FTS and MIPAS in this latitude and altitude range and the knowledge that MIPAS overestimates the methane compared to HALOE (Sect. 5, Payan et al., 2007).

Comparisons with HALOE do cover the NH winter midlatitude regions, in which we observe a negative bias of ACEFTS versus HALOE of the order of -5 to $-25 \%$ in the stratosphere ( $>700 \mathrm{~K}$ or above $\sim 25 \mathrm{~km}$ ). The comparisons with the NH mid-latitude and subtropical g-b FTIR stations (three stations in total) indicate a zero or negative bias of ACE-FTS of similar order of magnitude $(-6$ to $-12 \%)$ in the lower stratosphere $(<30 \mathrm{~km})$.

\subsection{Southern Hemisphere (SH)}

The only comparisons in the SH consist of the comparisons with HALOE in $(\mathrm{EqL} / \theta)$ space, and with ground-based FTIR stations. The former comparisons point to a slightly positive bias of ACE-FTS versus HALOE, of the order of $15 \%$ above $1000 \mathrm{~K}(\sim 35 \mathrm{~km})$ in local summer high latitudes. The negative bias observed in $\mathrm{NH}$ mid-latitude in winter may also exist in SH mid-latitude winter.

In the lower stratosphere $(12-30 \mathrm{~km})$, the most reliable, from a statistical point of view, comparisons with g-b FTIR data indicate a slightly negative bias of ACE-FTS (of the order of -5 to $-8 \%$ ) at southern mid-latitudes.

\subsection{General conclusions}

Overall one can say from the analyses of ACE-FTS $\mathrm{CH}_{4}$ VMR profiles in $(\mathrm{EqL} / \theta)$ space and their comparisons with HALOE, that the ACE-FTS data in the stratosphere are con- sistent with the meteorological fields. They also reproduce the variability of atmospheric methane very well. Based on the available comparisons with independent correlative data, we can also say that the ACE-FTS $\mathrm{CH}_{4}$ data have an overall accuracy that is within $10 \%$ in the upper troposphere lower stratosphere, and within $25 \%$ in the middle and higher stratosphere up to the lower mesosphere $(<60 \mathrm{~km})$. The observed biases are small and consistent with reported systematic uncertainties, to which the spectroscopic uncertainties are a large contribution. There are also indications for some seasonal and latitudinal dependence in the differences between ACE-FTS and correlative data.

Acknowledgements. The Atmospheric Chemistry Experiment (ACE), also known as SCISAT, is a Canadian-led mission mainly supported by the Canadian Space Agency and the Natural Sciences and Engineering Research Council of Canada. The SPIRALE balloon measurements could only be performed thanks to the technical team (L. Pomathiod, B. Gaubicher, G. Jannet); the flight was funded by ESA and the French space agency CNES for the ENVISAT validation project; the CNES balloon launching team is greatly acknowledged for successful operations. A. Hauchecorne is acknowledged for making available the MIMOSA advection model and F. Coquelet for useful help in the PV calculations and ACE data formatting. The g-b FTIR data providers are grateful to their national authorities for financial support; in Europe, additional support has come from the EU projects HYMN (http://www.knmi.nl/samenw/hymn) and UFTIR (http://www.nilu.no/uftir). Work at the Toronto Atmospheric Observatory was supported by NSERC, CFCAS, ABB Bomem, ORDCF, PREA, the University of Toronto, and a grant from the Canadian Space Agency. The National Center for Atmospheric Research is supported by the National Sience Foundation. The NCAR FTIR observation program at Thule is supported under contract by the National Aeronautics and Space Administration (NASA). Work at the Jet Propulsion Laboratory, California Institute of Technology was done under contract with the National Aeronautics and Space Administration (NASA). NASA grant NNG04GF39G and L. Harvey have supported the comparisons between HALOE and ACE-FTS. Thanks are due to William Daffer for his role in production of ACE and MLS Derived Meteorological Products.

Edited by: T. Wagner

\section{References}

Abrams, M. C., Chang, A. Y., Gunson, M. R., Abbas, M. M., Goldman, A., Irion, F. W., Michelsen, H. A., Newchurch, M. J., Rinsland, C. P., Stiller, G. P., and Zander, R.: On the assessment and uncertainty of atmospheric trace gas burden measurements with high-resolution infrared solar occultation spectra from space by the ATMOS experiment, Geophys. Res. Lett., 23, 2337-2340, 1996.

Barnet, C., Datta, S., and Strow, L.: Trace gas measurements from the Atmospheric Infrared Sounder (AIRS), in Optical Remote Sensing (Trends in Optics and Photonics Series Vol. 85), 89-92, 2003. 
Bernath, P. F., McElroy, C. T., Abrams, M. C., et al.: Atmospheric Chemistry Experiment (ACE): Mission overview, Geophys. Res. Lett., 32, L15S01, doi:10.1029/2005GL022386, 2005.

Boone, C. D., R. Nassar, K. A. Walker, Y. Rochon, S. D. McLeod, C. P. Rinsland, and Bernath, P. F. : Retrievals for the atmospheric chemistry experiment Fourier-transform spectrometer, Appl. Optics, 44 (33), 7218-7231, 2005.

Brasseur, G. P., Orlando, J. J., and Tyndall, G. S.: Atmospheric Chemistry and Global Change, Oxford University Press (New York, Oxford), 1999.

Espy, P. J. and Hartogh, P.: MIPAS: Potential of the experiment, data processing and validation of results, Special Issue in Atmos. Chem. Phys., 2006.

Fischer, H., Birk, M., Blom, C., Carli, B., Carlotti, M., von Clarmann, T., Delbouille, L., Dudhia, A., Ehhalt, D., Endemann, M., Flaud, J. M., Gessner, R., Kleinert, A., Koopman, R., Langen, J., Lpez-Puertas, M., Mosner, P., Nett, H., Oelhaf, H., Perron, G., Remedios, J., Ridolfi, M., Stiller, G., and Zander, R.: MIPAS: an instrument for atmospheric and climate research, Atmos. Chem. Phys., 8, 2151-2188, 2008,

http://www.atmos-chem-phys.net/8/2151/2008/.

Frankenberg, C., Meirink, J. F., van Weele, M., Platt, U., and Wagner, T.: Assessing methane emissions from global space-borne observations: Science, 308, 1010-1014, doi:10.1126/science.1106644, 2005.

GLOBALVIEW-CH4: Cooperative Atmospheric Data Integration Project - Methane. CD-ROM, NOAA ESRL, Boulder, Colorado; also available on Internet at http://www.esrl.noaa.gov/gmd/ccgg/ globalview/ch4/ch4_intro.html, 2005.

Gunson, M. R., Farmer, C. B., Norton, R. H., Zander, R., Rinsland, C. P., Shaw, J. H., and Gao, B. C.: Measurements of $\mathrm{CH}_{4}, \mathrm{~N}_{2} \mathrm{O}$, $\mathrm{CO}, \mathrm{H}_{2} \mathrm{O}$, and $\mathrm{O}_{3}$ in the middle atmosphere by the ATMOS experiment on Spacelab 3, J. Geophys. Res., 95, 13 867-13 882, 1990.

Gunson, M. R., Abbas, M. M., Abrams, M. C., et al.: The Atmospheric Trace Molecule Spectroscopy (ATMOS) experiment: Deployment on the ATLAS Space Shuttle missions, Geophys. Res. Lett., 23, 2333-2336, 1996.

Hase, F., Hannigan, J. W., Coffey, M. T., Goldman, A., Höpfner, M., Jones, N. B., Rinsland, C. P., and Wood, S. W.: Intercomparison of retrieval codes used for the analysis of highresolution, ground-based FTIR measurements, J. Quant. Spectrosc. Ra. Trans., 87, 25-52, 2004.

Hauchecorne, A., Godin, S., Marchand, M., Heese, B., and Souprayen, C.: Quantification of the transport of chemical constituents from the polar vortex to midlatitudes in the lower stratosphere using the high-resolution advection model MIMOSA and effective diffusivity, J. Geophys. Res., 107, 8289, doi:10.1029/2001JD000491, 2002.

Hoppel, K. W., Bowman, K. P., and Bevilacqua, R. M.: Northern Hemisphere summer ozone variability observed by POAM II, Geophys. Res. Lett., 26, 827-830, 1999.

López-Puertas, M., Funke, B., Gil-López, S., López-Valverde, M. A., von Clarmann, T., Fischer, H., Oelhaf, H., Stiller, G., Kaufmann, M., Koukouli, M. E., and Flaud, J.-M.: Atmospheric non-local thermodynamic equilibrium emissions as observed by the Michelson Interferometer for Passive Atmospheric Sounding (MIPAS), C.R. Physique, Elsevier SAS, 6, 848-862, 2005.

Manney, G. L., Michelsen, H. A., Santee, M. L., Gunson, M. R.,
Irion, F. W., Roche, A. E., and Livesey, N. J.: Polar vortex dynamics during spring and fall diagnosed using trace gas observations from the Atmospheric Trace Molecule Spectroscopy instrument, J. Geophys. Res., 104, 18 841-18 866, 1999.

Manney, G. L., Michelsen, H. A., Irion, F. W., Gunson, M. R., Toon, G. C., and Roche, A. E.: Lamination and polar vortex development in fall from ATMOS long-lived trace gases observed during November 1994, J. Geophys. Res., 105, 29 023-29 038, 2000.

Manney, G. L., Michelsen, H. A., Bevilacqua, R. M., Gunson, M. R., Irion, F. W. Livesey, N. J., Oberheide, J., Riese, M., Russell III, J. M., Toon, G. C., and Zawodny, J. M.: Comparison of satellite ozone observations in coincident air masses in early November 1994, J. Geophys. Res., 106, 9923-9944, 2001.

Manney, G. L., Santee, M. L., Livesey, N. J., Froidevaux, L., Read, W. G., Pumphrey, H. C., Waters, J. W., and Pawson, S.: EOS Microwave Limb Sounder observations of the Antarctic polar vortex breakup in 2004, Geophys. Res. Lett., 32, L12811, doi:10.1029/2005GL022823, 2005.

Manney, G. L., Daffer, W. H., Zawodny, J. M., Bernath, P. F., Hoppel, K. W., Walker, K. A., Knosp, B. W., Boone, C., Remsberg, E. E., Santee, M. L., Lynn Harvey, V., Pawson, S., Jackson, D. R., Deaver, L., McElroy, C. T., McLinden, C. A., Drummond, J. A., Pumphrey, H. C., Lambert, A., Schwartz, M. J., Froidevaux, L., McLeod, S., Takacs, L. L., Suarez, M. J., Trepte, C. R., Cuddy, D. T., Livesey, N. J., Harwood, R. S., and Waters, J. W.: Solar Occultation Satellite Data and Derived Meteorological Products: Sampling Issues and Comparisons with Aura MLS, J. Geophys. Res., 112, D24S50, doi:10.1029/2007JD008709, 2007.

McHugh, M., Magill, B., Walker, K. A., Boone, C. D., Bernath, P. F., and Russell, III, J. M.: Comparison of atmospheric retrievals from ACE and HALOE, Geophys. Res. Lett. 32, L15S10, doi:10.1029/2005GL022403, 2005.

Mondelain, D., Payan, S., Deng, W., Camy-Peyret, C., Hurtmans, D., and Mantz, A. W.: Measurement of the temperature dependence of line mixing and pressure broadening parameters between 296 and $90 \mathrm{~K}$ in the $\nu_{3}$ band of ${ }^{12} \mathrm{CH}_{4}$ and their influence on atmospheric methane retrievals, J. Mol. Spectrosc., 244, 130137, 2007.

Moreau, G., Robert, C., Catoire, V., Chartier, M., Camy-Peyret, C., Huret, N., Pirre, M., Pomathiod, L., and Chalumeau, G.: SPIRALE: a multispecies in situ balloon-borne instrument with six tunable diode laser spectrometers, Appl. Opt., 44(28), 59725989, 2005.

Nassar, R., Bernath, P. F., Boone, C. D., Manney, G. L., McLeod, S. D., Rinsland, C. P., Skelton, R., and Walker, K. A.: Stratospheric abundances of water and methane based on ACE-FTS measurements, Geophys. Res. Lett., 32, L15S04, doi:10.1029/2005GL022383, 2005.

Park, J. H., Russell III, J. M., Gordley, L. L., Drayson, S. R., Benner, D. C., McInerney, J. M., Gunson, M. R., Toon, G. C., Sen, B., Blavier, J.-F., Webster, C. R., Zipf, E. C., Erdman, P., Schmidt, U., and Schiller, C.: Validation of Halogen Occultation Experiment $\mathrm{CH}_{4}$ measurements from the UARS, J. Geophys. Res., 101(D6), 10 183-10 203, 1996.

Payan, S., Camy-Peyret, C., Oelhaf, H., Wetzel, G., Maucher, G., Kleim, C., Pirre, M., Huret, N., Engel, A., Volk, M. C., Kuellmann,H., Kuttippurath, J., Cortesi, U., Bianchini, G., Mencaraglia, F., Raspollini, P., Redaelli, G., Vigouroux, C., De Mazire, Mikuteit, S., Blumenstock, T., Velazco, V., Notholt, J., Mahieu, 
M., Duchatelet, P., Smale, D., Wood, S., Jones, N., M., Piccolo, C., Payne, V., Bracher, A., Glatthor, N., Stiller, G., Grunow, K., Jeseck, P., Ye, T., Pfeilsticker, K., and Butz, A.: Validation and data characteristics of methane and nitrous oxide profiles observed by MIPAS and processed with Version 4.61 algorithm, Atmos. Chem. Phys. Discuss., 7, 18043-18111, 2007, http://www.atmos-chem-phys-discuss.net/7/18043/2007/.

Piccolo, C. and Dudhia, A.: Precision validation of MIPAS-Envisat products, Atmos. Chem. Phys., 7, 1915-1923, 2007, http://www.atmos-chem-phys.net/7/1915/2007/.

Raspollini, P., Belotti, C., Burgess, A., Carli, B., Carlotti, M., Ceccherini, S., Dinelli, B. M., Dudhia, A., Flaud, J.-M., Funke, B., Höpfner, López-Puertas, M., Payne, V., Piccolo, C., Remedios, J. J., Ridolfi, M., and Spang, R.: MIPAS level 2 operational analysis, Special Issue MIPAS: Potential of the experiment, data processing and validation of results, edited by: Espy, P. J. and Hartogh, P., Atmos. Chem. Phys., 6, 5605-5630, 2006, http://www.atmos-chem-phys.net/6/5605/2006/.

Reber, C. A., Trevathan, C. E., McNeal, R. J., and Luther, M. R.: The Upper Atmosphere Research Satellite (UARS) mission, J. Geophys. Res., 98, 10 643-10 647, doi:10.1029/92JD02828, 1993.

Remedios, J. J., Ruth, S. L., Rodgers, C. D., Taylor, F. W., Roche, A. E., Gille, J. C., Gunson, M. R., Russell III, J. M., Park, J., Zipf, E. C., and Erdman, P. W.: Measurements of methane and nitrous oxide distributions by the improved stratospheric and mesospheric sounder: Retrieval and validation, J. Geophys. Res., 101, 98439871, 1996.

Remedios, J. J.: Extreme Atmospheric Constituent Profiles for MIPAS, Proceedings of the European symposium on atmospheric measurements from space, ESTEC, Netherlands, 20-22 January, 2, 779-783, 1999.

Remedios, J. J., Leigh, R. J., Waterfall, A. M., Moore, D. P., Sembhi, H., Parkes, I., Greenhough, J., Chipperfield, M. P., and Hauglustaine, D.: MIPAS reference atmospheres and comparisons to V4.61/V4.62 MIPAS level 2 geophysical data sets, Special Issue "MIPAS: Potential of the experiment, data processing and validation of results", edited by: Espy, P. J. and Hartogh, P., Atmos. Chem. Phys. Discuss., 7, 9973-10017, 2007, http://www.atmos-chem-phys-discuss.net/7/9973/2007/.

Ridolfi, M., Carli, B., Carlotti, M., von Clarmann, T., Dinelli, B. M., Dudhia, A., Flaud, J.-M., Höpfner, M., Morris, P. E., Raspollini, P., Stiller, G., and Wells, R. J.: Optimized forward model and retrieval scheme for MIPAS near-real-time data processing, Appl. Opt., 39, 1323-1340, 2000.
Roche, A. E.,Kumer, J. B., Nightingale, R. W., Mergenthaler, J. L., Ely, G. A., Bailey, P. L., Massie, S. T., Gille, J. C., Edwards, D. P., Gunson, M. R., Abrams, M. C., Toon, G. C., Webster, C. R., Traub, W. A., Jucks, K. W., Johnson, D. G., Murcray, D. G., Murcray, F. H., Goldman, A., and Zipf, E. C.: Validation of $\mathrm{CH}_{4}$ and $\mathrm{N}_{2} \mathrm{O}$ measurements by the CLAES instrument on the Upper Atmospheric Research Satellite, J. Geophys. Res., 101, 9679 9710, 1996.

Rodgers, C. D.: Inverse methods for atmospheric sounding: Theory and Practice, Series on Atmospheric, Oceanic and Planetary Physics, 2, World Scientific Publishing Co., Singapore, 2000.

Rodgers, C. D. and Connor, B. J.: Intercomparison of remote sounding instruments, J. Geophys. Res., 108, 4116-4129, 2003.

Rothman, L. S., Jacquemart, D., Barbe, A., Chris Bennerc, D., Birk, M., Brown, L. R., Carleer, M. R., Chackerian Jr., C., Chance, K., Coudert, L. H., Dana, V., Devi, V .M., Flaud, J.-M., 30 Gamache, R. R., Goldman, A., Hartmann, J.-M., Jucks, K. W., Maki, A. G., Mandin, J.-Y., Massie, S. T., Orphal, J., Perrin, A., Rinsland, C. P., Smith, M. A. H., Tennyson, J., Tolchenov, R. N., Toth, R. A., Vander Auwera, J., Varanasi, P., and Wagner, G.: The HITRAN 2004 molecular spectroscopic database, J. Quant. Spectrosc. Ra. Trans., 96, 139-204, 2005.

Russell, J. M., III, Gordley, L. L., Park, J. H., Drayson, S. R., Tuck, A. F., Harries, J. E., Cicerone, R. J., Crutzen, P. J., and Frederick, J. E.: The Halogen Occultation Experiment, J. Geophys. Res., 98, 10777-10 797, 1993.

Schoeberl, M. R., Lait, L. R., Newman, P. A., and Rosenfield, J. E.: The structure of the polar vortex, J. Geophys. Res., 97, 78597882, 1992.

Schoeberl, M. R., Luo, M., and Rosenfield, J. E.: An analysis of the Antarctic Halogen Occultation Experiment trace gas observations, J. Geophys. Res., 100, 5159-5172, 1995.

Vigouroux, C., De Mazière, M., Errera, Q., Mahieu, E., Duchatelet, P., Wood, S., Smale, D., Mikuteit, S., Blumenstock, T., Hase, F., and Jones, N.: Comparisons between ground-based FTIR and MIPAS $\mathrm{N}_{2} \mathrm{O}$ and $\mathrm{HNO}_{3}$ profiles before and after assimilation in BASCOE, Atmos. Chem. Phys., 7, 377-396, 2007, http://www.atmos-chem-phys.net/7/377/2007/.

Wahlen, M.: The Global Methane Cycle, Annu. Rev. Earth Pl. Sc., 21, 407-426, 1993. 